\title{
BREVE DIÁLOGO TRANSDISCIPLINAR SOBRE TEORIAS, PRÁTICAS E METODOLOGIAS CARTOGRÁFICAS
}

\author{
Maurício Camargo Panella ${ }^{1}$
}

\section{Resumo}

Este artigo tem como objetivo central estabelecer um diálogo sobre reflexões e projetos colaborativos realizados por pensadores, artistas e coletivos que criam, vivenciam e elaboram práticas e teorias sobre cartografia social, ambiental e artística.

Palavras chaves: cartografia, estética, arte sonora, psicogeografia, arte contemporânea.

\section{Abstract}

This article is mainly aimed to provide a mapping of reflections and collaborative projects undertaken by thinkers and artists / groups that are created experience and elaborate practices and theories about social, environmental and artistic cartography. (mudei o cart.. de lugar).

Key words: cartography, aesthetics, sound art, psychogeography, Contemporary Art.

\footnotetext{
${ }^{1}$ Antropólogo, sociólogo e artista multimídia. Doutorando pela Facultad de Bellas Artes de Granada- Espanha. Fundador do Instituto Casadágua- Arte, Educação e Sustentabilidade. Pesquisador do Núcleo de Estética e Semiótica- Programa de Pós Graduação de Arquitetura e Urbanismo da UNB.
} 
Em resposta à desorientação que as sociedades contemporâneas vivem, ao avanço de um panorama humano demarcado por discriminações sociais, econômicas, culturais e religiosas e, ainda, pelas amostras de devastação ambiental que ocorrem por todas as regiões do mundo, achamos prudente traçar uma rede de comunicação entre teóricos, pesquisadores e criadores que investigam outros modos de interação social e com o mundo, predispostos a compreender, aprender, interagir, viver e construir uma relação orientada por princípios ecosóficos ${ }^{2}$. Princípios estes que permitam uma abertura do espírito humano a uma cosmovisão multidimensional mais ética e poética que também esteja ancorada por meios e métodos que dialoguem e valorizem os aspectos mais sutis, oníricos, simbólicos, criativos e subjetivos. E que, principalmente, devolvam a esperança nas relações sócias.

A investigação sócio-cultural e os processos de criação artística e cartográfica transdisciplinares e interculturais que levamos a cabo nos últimos anos, nos possibilitou realizar um breve mapeamento de instituições, coletivos, pesquisadores e artistas, em distintos lugares do mundo, que anseiam e criam novas vias e possibilidades de pesquisar, registrar, experimentar e significar os modos de interação humana no mundo de forma mais sensível.

Após a criação de uma série de produtos e instalações lúdicas, coletivas e interativas, da elaboração de metodologias pedagógicas e do desenvolvimento de tecnologias sociais junto a Universidades, Centros, Museus e laboratórios nômades com o apoio de instituições municipais, estaduais, federais e internacionais - principalmente por meio das ações criativas e das metodologias pedagógicas elaboradas especificamente pelo Projeto De Fora adentro Cartografia dos Sentidos ${ }^{3}$-, achamos adequado tecer estes saberes que ora se comunicam em simpósios, residências e bienais, ora se tocam em congressos, vez ou outra se conhecem e se apresentam por páginas de internet. Desde nossas áreas focais, das artes e das ciências sociais, apostando num modelo epistemológico rizomático ${ }^{4}$, nos aproximamos e nos ligamos a uma extensa rede. Ligar intuições e conclusões abertas e comunicar experiências é o objetivo deste presente trabalho. Conscientes que pesquisas, metodologias e teorias cartográficas são

\footnotetext{
${ }^{2}$ Ecosofia: Felix Guattari afirma que apenas por uma articulação ético-política, que ele chama de ecosofía, que se dá entre os três registros ecológicos (o do meio ambiente, o das relações sociais e o da subjetividade humana), é que a Humanidade será capaz de abrir novas perspectivas de convívio co-responsável.

${ }^{3}$ O projeto De Fora adentro - Cartografia dos Sentidos, foi lançado na $62^{\circ}$ Reunião da SBPC na Cidade de Natal. Coordenado pelo Instituto Casadágua - Arte, Educação e Sustentabilidade, foi amparado pelo Núcleo de Arte e Cultura da Universidade Federal do Rio Grande do Norte, recebendo apoios de Fundações de Pesquisa e Secretarias de Educação, Cultura. https://casadagua.wordpress.com/

${ }^{4}$ Em 1970 Deleuze e Guatarri desenvolvem o modelo epistemológico tomando como metáfora a estrutura de um rizoma. Segundo a biologia é um conjunto de ramas que formam uma estrutura maior.
} 
bastantes extensas e multiformes; e que muitas das intuições do sujeito criador partem de uma inquietação nascida não somente no individuo, mas sim como uma pulsação de uma rede social autopoiética auto organizadora.

Nossos interesses em compor produtos e informações e desenvolver instalações lúdicas, midiáticas, interativas, poéticas e coletivas possibilitou um entrecruzar de pensamentos, criações e propostas. A “criação de mundos", por meio de instalações, objetiva que o público desvende e abra em si mesmo, na relação com o outro e com o mundo, percepções e entendimentos permeados por canais racionalizantes e sensíveis. Quando começamos a pesquisar as possibilidades de criar instalações cartográficas colaborativas, almejávamos a criação de interfaces que redimensionassem a percepção espaço temporal. A obra de arte e, em particular e mais intensamente ainda, os processos de criação artística contemporâneos, implicam numa releitura do sujeito consigo mesmo, com suas capacidades imaginativas, de geração e acesso à uma subjetividade multidimensional que permita uma recomposição do sujeito com o mundo.

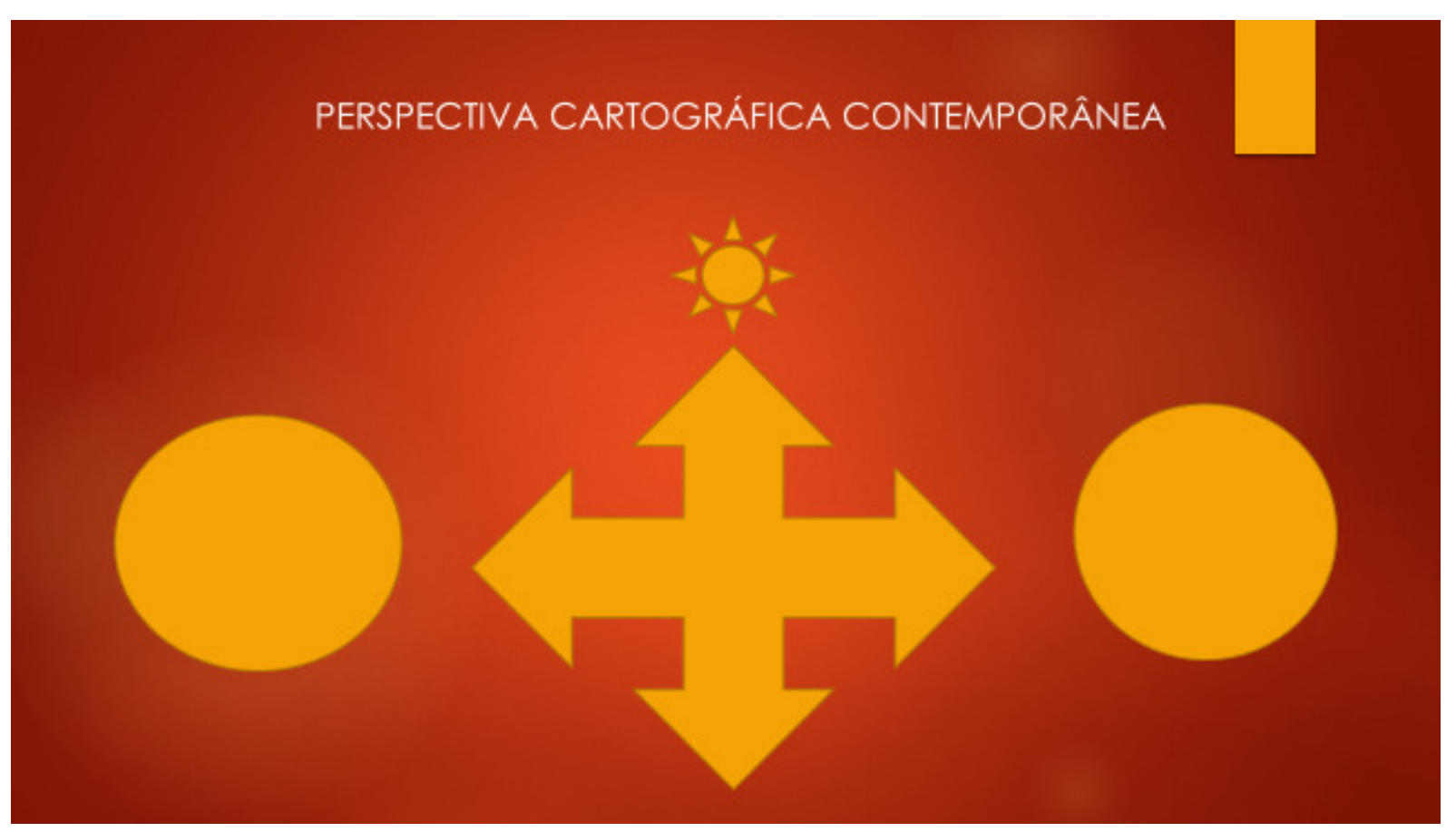

Figura 1 - Perspectiva Cartográfica Contemporânea 


\section{DA APROPRIAÇÃO SUBJETIVA}

Após nossas longas e sem fim investigações sobre processos cartográficos chegamos a compor alguns gráficos que apresentam ideias e autores que também se detiveram em pesquisar o tema. Alguns pensadores contemporâneos vêm discutindo sobre a importância em recuperar os sentidos de apropriação subjetiva e imaginativa que foram sendo postos de lado por um sistema planificado e padronizado, efeitos principalmente sentidos nos grandes centros urbanos onde a estrutura concreta estabelece caminhos e rotas fixas. Num mundo globalizado, onde imperam formas únicas de entender e interagir com o mundo, perde-se a profundidade e a diversidade de impressões e concepções que cada sujeito e cada cultura tem e pode oferecer na construção de um conhecimento multifacetário.

Nossos estudos também apontaram suas investigações para as fraturas geradas por um pensamento unidirecional que não reconhece as potencialidades artísticas, criativas e imaginárias como formas de conhecimento válidas para a ciência e para a auto-organização do sistema mundo. Da mesma forma como também atentamos para os danos causados pelo escanteamento e pelo massacre de tantas cosmovisões tradicionais milenárias, estas que estabelecem relações mais respeitosas entre os sujeitos e o entorno ambiental.

Este trabalho visa, deste modo, construir uma ponte entre alguns eixos e métodos de pesquisa instaurados por nós e encontrados em outros autores para poder elaborar um mapa sobre estudos cartográficos:

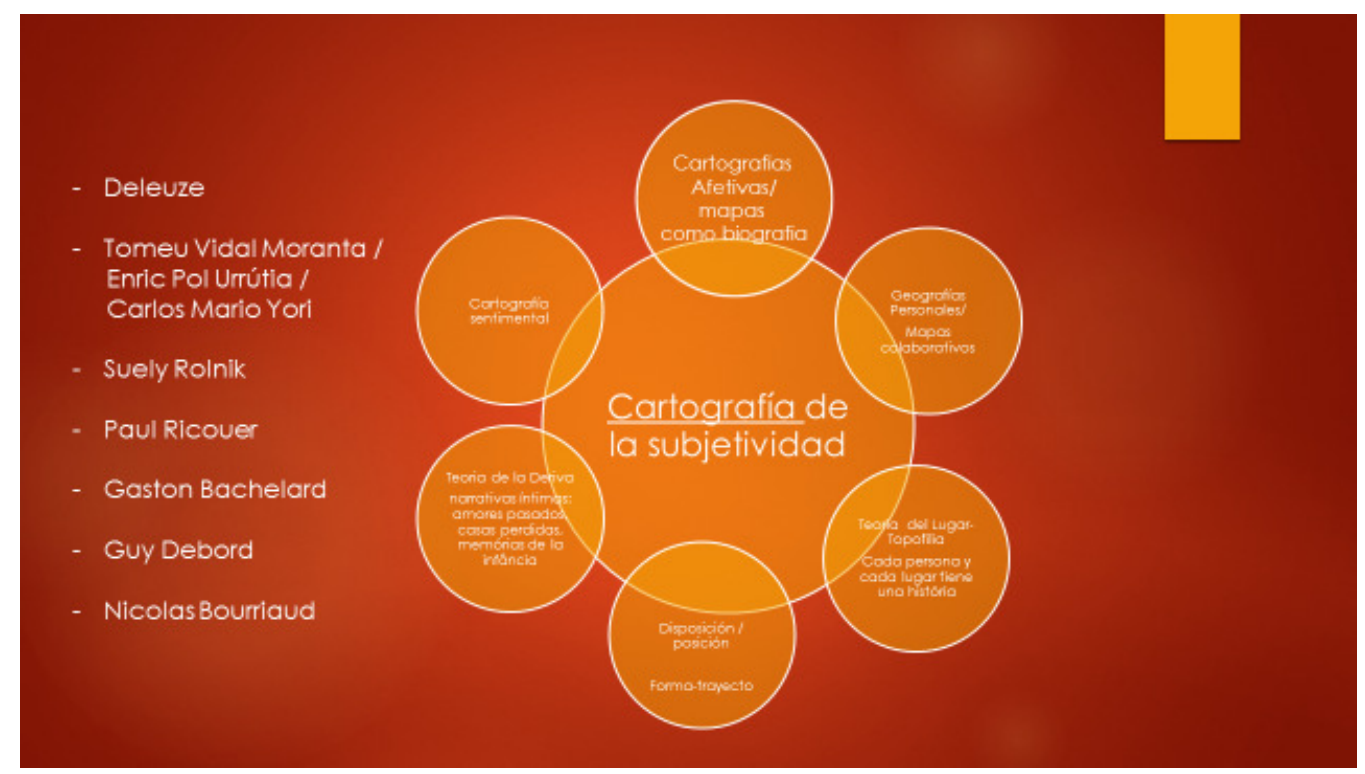

Figura 2 - Cartografia da Subjetividade 
Todos os nossos estudos se expandiram de modo natural e fluído, em consonância com as ideias bem desenvolvidas por Nicolas Bourriaud, fundamentadas por uma estética relacional radicante, absorvendo e desenvolvendo processos criativos e reflexivos que foram sendo construídos em rede, crescendo suas raízes a medida em que os temas foram avançando. Bourriaud acredita no papel emancipador da arte e percebe como os artistas contemporâneos elaboram seus processos de pesquisa absorvendo informações de fontes as mais variadas. As cartografias artísticas são fundadas por um espírito de nomadismo, nas próprias deambulações dos artistas, em suas variadas formas de apropriação de mundo, imaginárias, físicas, culturais, informáticas. Este pensador nomeou este formato de apropriação de mundo como formas-trajeto. Nelas os criadores percebem como são criados por contextos e formatos heterogêneos, o que promove uma redefinição de identidade, muito mais aberta à interculturalidade, aberta à transcodificação de signos e símbolos que estão expostos cotidianamente no mundo. $\mathrm{O}$ que de certa forma favorece um comportamento mais propício para o intercâmbio de conhecimentos.

A este processo de apropriação, entendimento e, consequentemente, de expressão radicante, que se expande infinitamente, podemos também equiparar as noções que Deleuze desenvolveu de territorialização, desterritorialização e reterritorialização, que vai do se perder ao se (re)orientar, onde podemos identificar três instâncias espaço-temporais dessas relações: orientação, desorientação e reorientação; aqui, o estado desterritorializante seria o instante de passagem do momento de territorializar um espaço e um tempo em direção a uma reterritorialização subjetivada, modificada, atualizada, transformada pela relação.

Algumas ideias destes autores estão imbuídas com os pensamentos situacionistas, principalmente erguidos pela Teoria da Deriva ${ }^{5}$ desenvolvida por Guy Debord. O pensamento situacionista aposta em modos de apreender o mundo expressos pelo caminhar à deriva do errante, um caminhar despretencioso, que não busca alcançar metas e está aberto à absorção dos conteúdos oferecidos pelo presente e capturados pela percepção devaneante. A aposta, a busca do errante, seria precisamente a de alcançar este momento do desterritorializar, de permitir-se perder, de desenvolver e potencializar outras formas de absorção das informações expostas e lançadas no mundo; um estado efêmero de desorientação espacial que desperta outras leituras de mundo além das que a sociedade do espetáculo lança.

\footnotetext{
5 Teoria da Deriva: Os surrealistas e, posteriormente, os situacionistas da década de 1960, entenderam a cidade como um terreno a ser redescoberto por um olhar novo, por uma perspectiva de um viajante numa aventura, o que suscitava um modo de experimentar todo tipo de vivência abrindo-se para novos encontros.
} 
Trabalhos desenvolvidos e orientados por tais perspectivas vem sendo desenvolvidos em vários locais do mundo. Um trabalho importante é o desenvolvido pelo "Osservatório Nómade"*:

O Ossevatorio Nomade propõe métodos de intervenção espacial baseados nas práticas de exploração, escuta e de relação com os ambientes, os habitantes e as suas memórias. Tal prática pretende catalisar o desenvolvimento de processos flexíveis e de auto-organização, mediante o estabelecimento de novas relações sociais e ambientais. As intervenções permitem um levantamento sensível, complexo e dinâmico dos territórios e das comunidades. Graças à abordagem interdisciplinar, estas experiências tornam-se apelativas e de fácil acessibilidade, revelando um modus operandi único para partilhar conhecimentos e contribuir para a difusão da consciência das comunidades relativamente aos seus territórios e ambiente cultural. Como consequência, nascem respostas eficazes e de participação criativa à administração territorial e urbana. (Dossier Walkshop - Aqueduto das Águas Livres: um percurso através das realidades materiais e imateriais da metrópole contemporânea Lisboa, ano 2009)

No Brasil Paola Berenstein vem realizando desde o Laboratório Urbano/ Programa de Pós Graduação em Arquitetura e Urbanismo da Universidade Federal da Bahia, estudos e práticas de trabalho de campo com bases em metodologias que buscam um sentido de apropriação do espaço urbanístico mediado pela experiência corpórea, táctil, sensível. Corpocidade, plataforma criada junto a outros intelectuais e artistas, difunde as experiências de apreensão da cidade realizadas nos encontros interdisciplinares que o Laboratório realiza. Este é um espaço virtual onde se encontram ideias e pensamentos

[...] em torno do processo de espetacularização das cidades contemporâneas e a consequente pacificação dos espaços públicos, propondo um formato de encontro fundado na ideia de composição coletiva: um modo de abordagem sobre o complexo engendramento das inúmeras formas de divergência que estão em disputa nas diferentes narrativas da experiência urbana, baseado no exercício de articulação entre os diferentes conteúdos dessa trama, numa dinâmica de estudo intensivo sobre as possibilidades de composição conjunta de constelações de ideias sobre experiências de apreensão da cidade.

(https://corpocidade4.wordpress.com/apr.esentacao)

A valorização de um pensamento psicogeográfico, de um modo de captura de mundo que aposta na apreensão do mundo realizada também pelos sentidos e pelos sentimentos que chegam ao sujeito, vem sendo fundamentais para as pesquisas dirigidas pelos profissionais da área da psicologia ambiental. Autores e pesquisadores contemporâneos desta disciplina como Tomeu Vidal Moranta e Enric Pol Urrútia vem se debruçando em investigações sobre a temática relacionada a apropriação do espaço. Estes autores dirigem suas pesquisas sobre a relação que fundamenta os vínculos das pessoas com os lugares e como esses vínculos 
estabelecem a identidade do sujeito e a identidade social, tomando como imprescindível em suas análises as percepções que os sujeitos têm com o espaço simbólico, para assim se construir uma noção social de espaço público, da mesma forma como o sentido de cidadania e sustentabilidade.

Os conceitos e estudos iniciais sobre os aspectos fenomenológicos de apropriação do espaço (psicologia do espaço) desenvolvidos por Perla Korosec Sefarty em 1976 na Conferencia en Estrasburgo ${ }^{6}$, tratam de observar os aspectos dinâmicos da interação da pessoa com o meio. Algumas das conclusões tomadas partem do principio de um modelo dual de apropriação, próximo das idéias de Bourriaud e Deleuze. Os pensadores da psicología ambiental tomam como parâmetro para suas análises as formas de ação e transformação instauradas pelos sujeitos no processo de territorialização do espaço público.

Para os pesquisadores desta área o ato de deixar pegadas nos espaços públicos acaba por incorporar processos cognitivos e ativos nos sujeitos, o que, por fim, fixa sentidos dotados de significado nos sujeitos. As marcas fixadas e deixadas são rastros que uma pessoa acompanha em seu lugar, o que desenvolve finalmente o sentimento de apropriação. Essa identificação simbólica diretamente tatua as memórias de interação com outros sujeitos e com o meio, e são reconhecidos com o passar do tempo. Quanto mais espaços são gerados de forma coletiva e quanto mais o reconhecimento da construção da memória física fica registrado nos espaços, maior é a a coesão social e, consequentemente, maior é a responsabilidade atribuída ao grupo. O sentido de apropriação do espaço promove e desenvolve um papel importante no proceso cognitivo sobre o conhecimento, a categorização e a orientação dos lugares e dos afetos, e consequentemente, da auto-estima.

$\mathrm{Na}$ Espanha vem sendo gestadas por alguns coletivos ações colaborativas que partem do exercício de cartografar o meio e as impressões que os sujeitos tem sobre os seus lugares. transductores $^{7}$ é uma destas propostas interdisciplinares que desenvolvem métodos pedagógicos formando comunidades de aprendizagem em rede que se dedicam a cartografar os ritmos, os saberes e os tempos dos agentes, objetivando a interferência nos espaços

\footnotetext{
${ }^{6}$ Conferencia en Estrasburgo: A celebração de uma conferência internacional na cidade de Estrasburgo no ano 1976, promovida por Perla Korosec-Serfaty, trouxe visibilidade ao conceito de apropriação do espaço dentro da comunidade científica.

${ }^{7}$ Transductores: Transductores é uma plataforma interdisciplinar que realiza projetos de investigação e mediação com três focos principais de interesse: as pedagogias coletivas, as práticas artísticas colaborativas e os modos de intervenção na esfera pública. http://transductores.net.
} 
públicos, entidades e redes diversas, desenhando e organizando projetos pedagógicos colaborativos.

A construção da identidade do sujeito e a construção da identidade coletiva pelo reconhecimento dos contéudos oníricos, subjetivos e imaginativos dos sujeitos também são abordadas por Paul Ricouer. Este autor sustenta suas ideias na importância que a narratividade da história pessoal tem para a construção do sentido de responsabilidade e ética entre os indivíduos. Dessa forma, um dos objetivos da hermenêutica, na filosofia ricoeuriana, é estabelecer a condição de possibilidade de interpretação do si, na qual o indivíduo compreende a si mesmo narrando suas próprias experiências. O "interpretar" passa a significar a possibilidade de imaginar a situação proposta pelo texto e, em seguida, compreendê-lo na singularidade de nossa vida, nas situações de nosso cotidiano.

O alargamento desta forma de interpretação realizada pelo sujeito, ao expandir-se para o coletivo possibilita, na hermenêutica ricouriana, a condição do desenvolvimento de uma identidade idem e identidade ipse $^{8}$, onde o sentido de co-responsabilidade e promessa entre indivíduos, conscientes dos processos de individualização do outro, abre e instaura uma consciência coletiva, um sentido de cidadania desenvolvido pelo próprio sujeito.

Estas novas interpretações e teorizações sobre o redimensionamento do sentido de apropriação do mundo foram lançadas por Gaston Bachelard em seu célebre e inspirador livro A Poética do Espaço. Bachelard, em sua fenomenologia da imaginação criadora, abordou incansavelmente os modos de apreensão do mundo e de inter-relação do sujeito com as coisas do mundo. Nesta obra mestra, inspiradora tanto para os pesquisadores da psicologia ambiental, como para antropólogos, sociólogos e coletivos de artistas contemporâneos, Gaston Bachelard esmiúça os pequenos mundos subjetivos, oníricos, imaginados pelo sujeito, atribuindo significações que amplificam a compreensão das relações estabelecidas e percebidas somente pela via racional.

Essa gama ampla de teorias que vem sendo constituídas por pensadores da contemporaneidade, assim como o crescente desenvolvimento de projetos artísticos e sociais fundamentados por processos cartográficos que valorizam a subjetividade, o onirismo e

\footnotetext{
${ }^{8}$ Identidade Idem e Identidade Ipse: $\mathrm{O}$ idem se entende como a neutralização impessoal de uma existência, o indivíduo não como pessoa, mas como entidade neutra. É uma identidade estática, atemporal, abstrata. O ipse manifesta a presença do si próprio em uma pessoa. Esta é uma identidade dinâmica, temporal, que inclui mudanças.
} 
imaginação, nos anima a pensar que nossos propósitos caminham em direção a uma ânsia coletiva por novos modelos de apreensão de mundo e de responsabilidade coletiva.

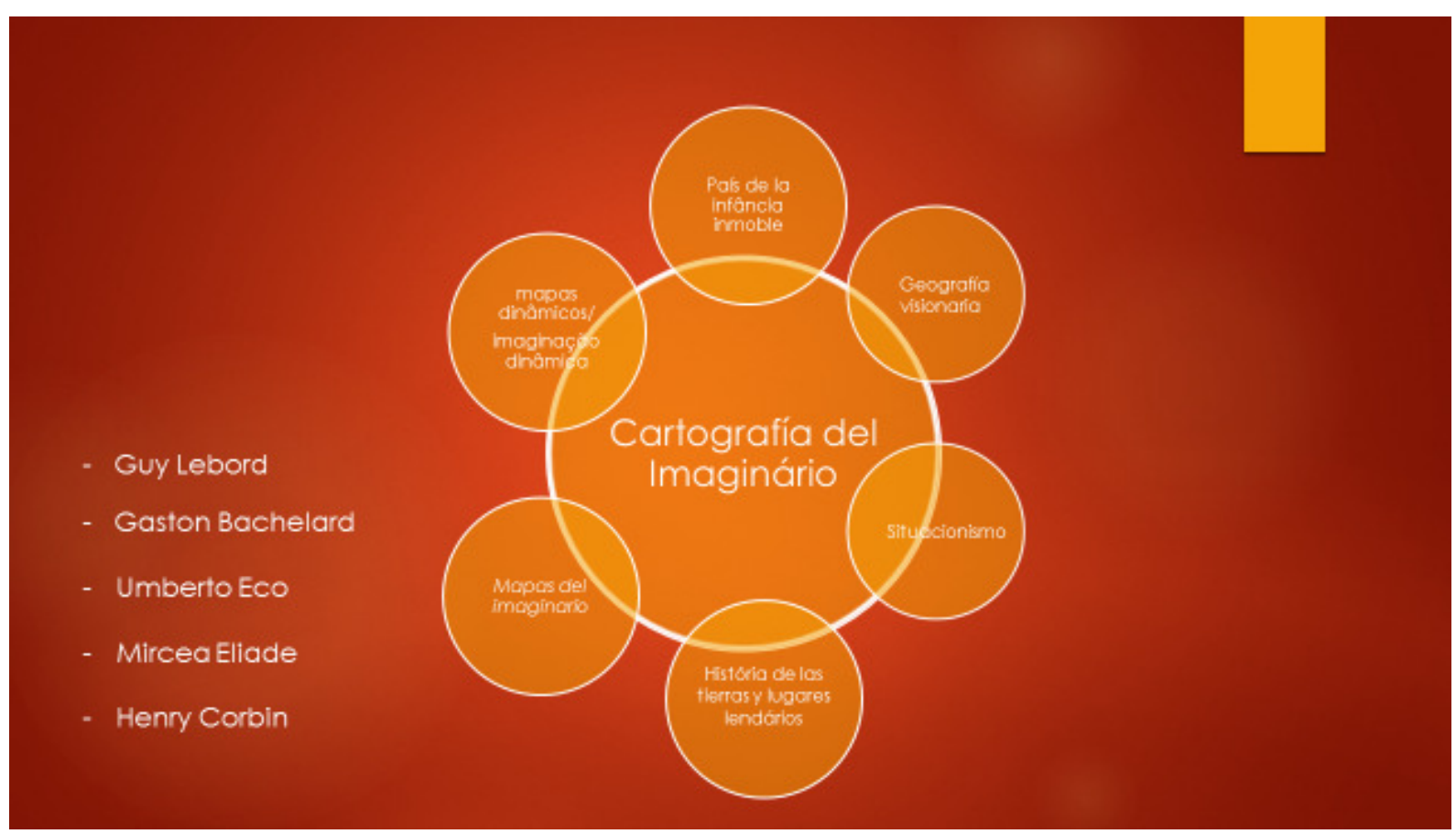

Figura 3 - Cartografia do Imaginário

Conforme aprofundamos os estudos e as perspectivas de investigação cartográfica vamos descobrindo em nós mesmos, em outros artistas e pesquisadores e no mundo, um universo de possibilidades criativas e investigativas infinitas que amplia nossos caminhos de abordagem e de percepções imaginativas. As cartografias podem ser sobre planos, podem ser sobre as imagens visuais, podem ser textuais, podem ser verticais e cortantes. As cartografias podem ser mentais, sonoras, áudio-visuais, literárias. Nesse universo sem fim de possibilidades da abordagem cartográfica fomos reunindo alguns autores que direcionaram seus estudos sobre o imaginário:

\section{Do imaginário}

Dentre alguns destes autores Gaston Bachelard reaparece, e é, sem dúvida, um incansável anunciador das potências que a imaginação traz ao indivíduo pelas formas mais sensíveis de experimentar o mundo subjetivo e o mundo concreto das coisas, e de então nomeá-las. Suas obras sobre as Poéticas, do Espaço, do Devaneio, assim como seus livros 
sobre imaginação material, e suas contribuições sobre a percepção temporal, oferecem uma metodologia cartográfica de abordagem e percepção espaço-temporal que rompem os véus que limitam a interação com o mundo somente por uma mirada racionalizante.

Quando o tema é a cartografia de espaços e tempos sagrados, ritualizados, encontramos autores como Henri Corbin e Mircea Eliade que nos trazem estudos e pesquisas sobre uma interação humana aberta a experiências com um espaço invisível e com um tempo atemporal. As idéias destes autores trazem símbolos religiosos e de conteúdo psíquico absorvidos sob estados de percepção diferenciados. São estados da alma que revelam e cohabitam em muitas culturas e regiões do mundo. As cartografias rituais expressas por estes autores são cartografias desenvolvidas em estados alterados de consciência, cartografias mentais, intuitivas. O artista contemporâneo Francisco Villaslobos vem desenvolvendo uma série de performances pictográficas e musicais que se aproximam muito de práticas xamânicas. Algumas das obras deste artista partem de mapas mentais que interligam conceitos, obras, grafismos, sons. ${ }^{9}$

Humberto Eco é outro autor que realiza um mapeamento do universo imaginário. Proporciona um passeio recheado de encantamento e possibilidades surreais por meio de imagens pictográficas que muitos artistas fizeram sobre territórios lendários. Neste ensaio ilustrado, Umberto Eco discorre sobre a história de lugares como Camelot, Atlântida, o paradeiro do Santo Graal, Lemúria, a Ilha de Salomão. Aliando uma antologia de textos à uma pesquisa iconográfica impecável, o autor descreve o que há de interessante por trás das terras que fascinaram tantos artistas ao longo dos séculos. Como Bachelard, mergulha numa literatura que deflagra o inconsciente humano. Se Bachelard se dirige às fantasias imaginárias do sujeito, Eco, em seu livro Histórias das Terras e Lugares Lendários, viaja pela audácia humana que cria sem limites mundos imaginários, muitas vezes não apreensíveis pela realidade.

\footnotetext{
${ }^{9}$ Ver ensaio deste autor publicado nesta edição: Pensamiento visual y geografía imaginaria.
} 


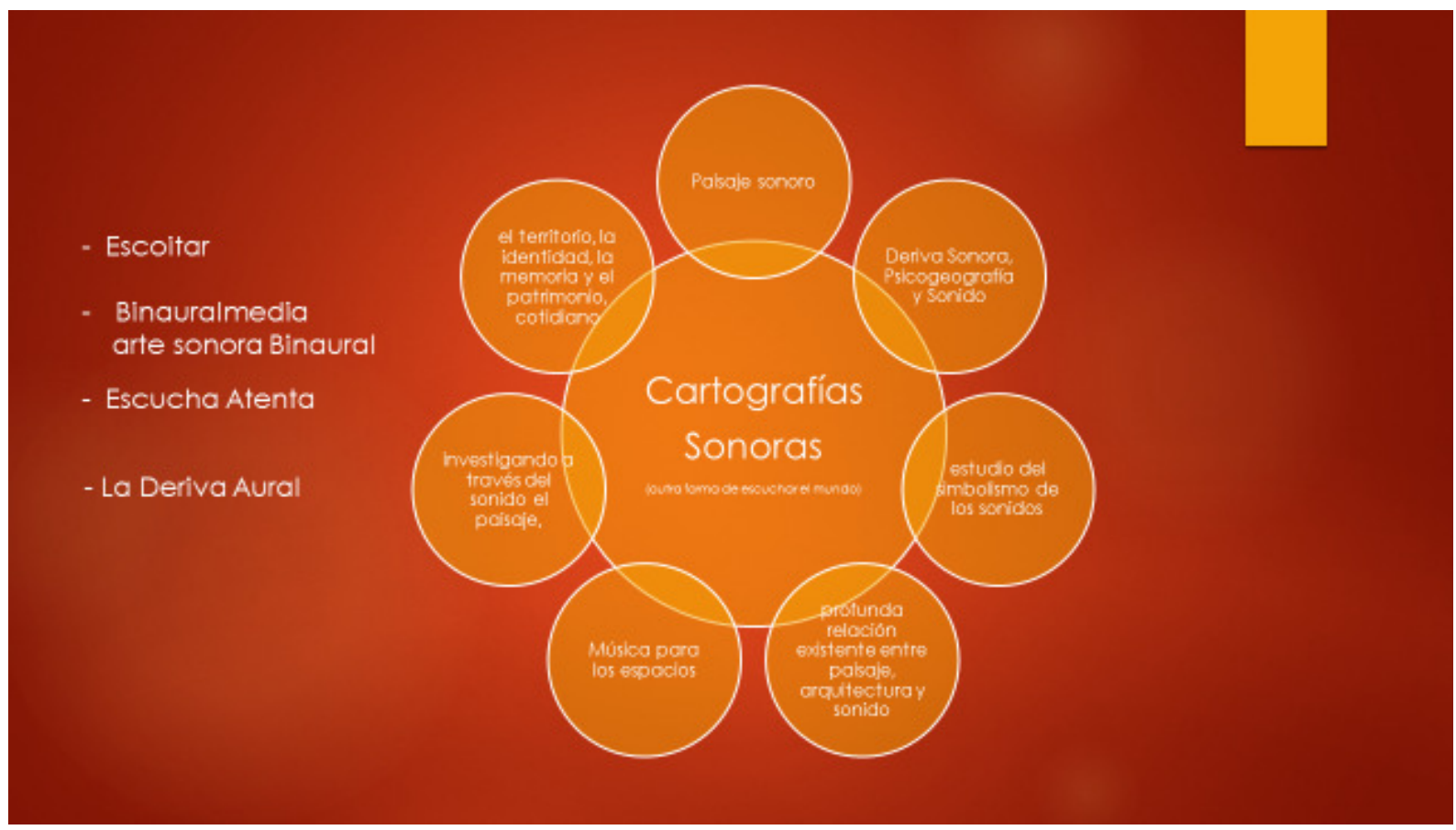

Figura 4 - Cartografias Sonoras

\section{Das sonoridades}

Aterrissamos nossas atenções para as cartografias colaborativas interdisciplinares concebidas e coordenadas por coletivos e centros de pesquisa social e artística. Nossos anseios atuais em realizar derivas sonoras para captar os ritmos da cidade no Projeto De Fora Adentro nos foram levando a conhecer projetos de cartografia sonora.

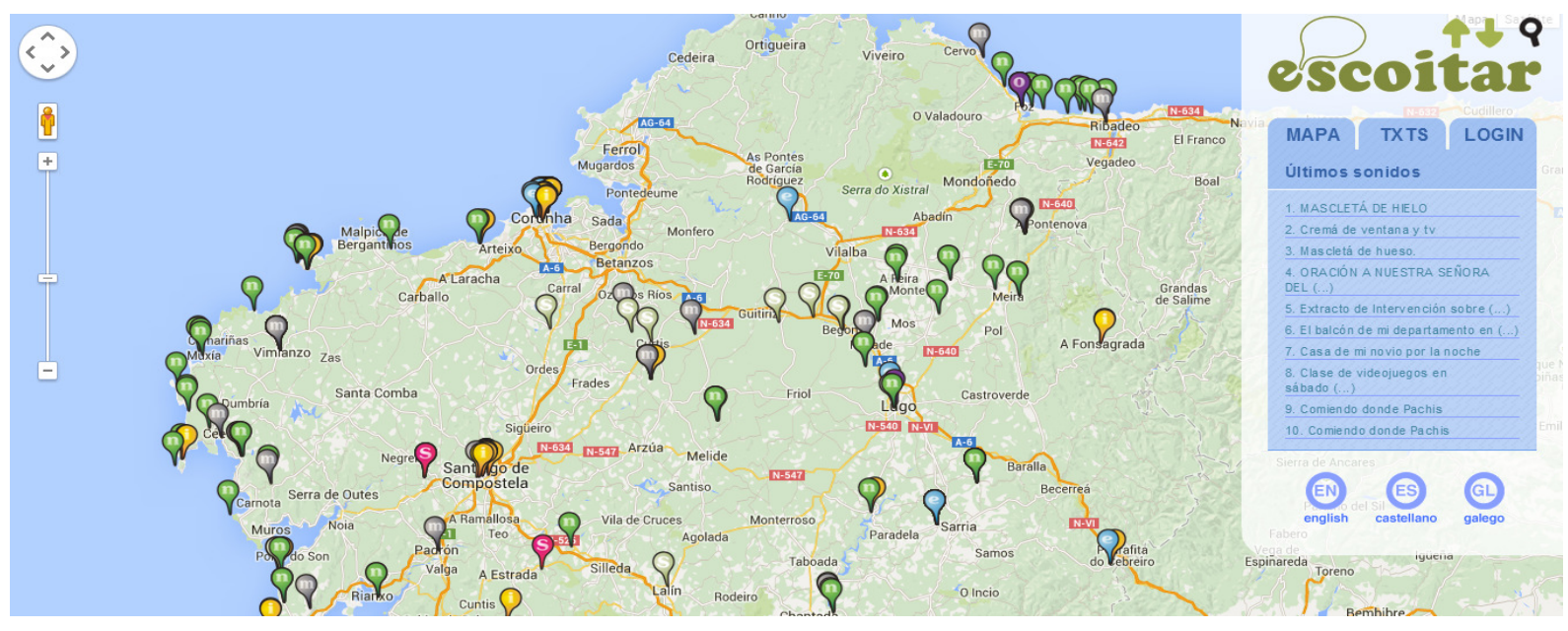

Figura 5 - Mapa "Escoitar" 
Um epicentro bastante destacado da Cartografia Sonora encontra-se na Espanha, onde algumas instituições e coletivos, como o Escoitar $^{10}$ na Galícia, que vem mapeando, capturando e difundindo em sua plataforma virtual os registros sonoros de manifestações culturais em risco de desaparecimento.

Também em Portugal a organização Binaural $\operatorname{Nodar}^{11}$ vem há mais de 10 anos coordenando projetos colaborativos pedagógicos tendo como objetivo central a pesquisa, o mapeamento e o registro sonoro. Este coletivo, coordenado por Luís Costa ${ }^{12}$ e Manuela Barile, tem como objetivo central a promoção, a exploração e a pesquisa nos domínios da arte sonora experimental, com especial ênfase na transversalidade de mídia e linguagens e na articulação entre a produção artística e o contexto envolvente, particularmente ao desenvolver atividades nos espaços rurais.

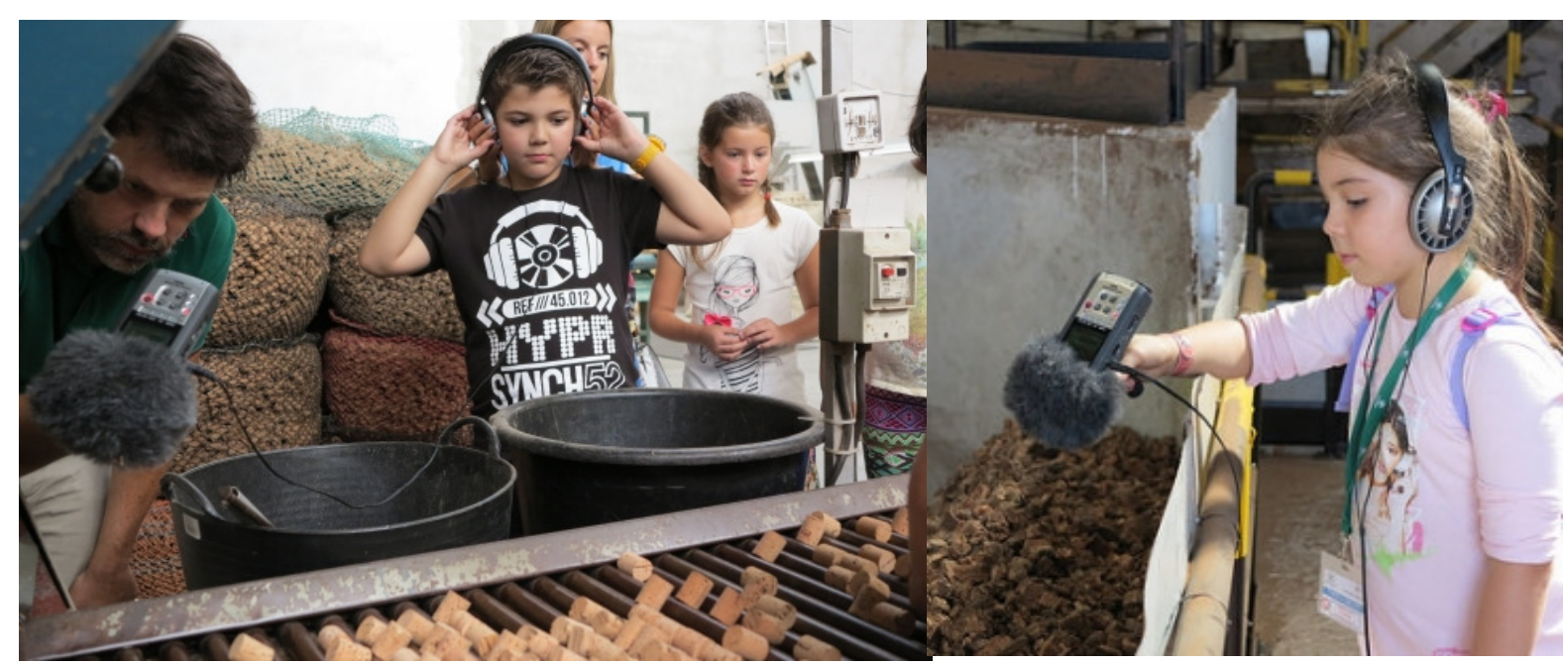

Figuras 6 e 7 - A Memória Sonora da Cortiça é uma instalação sonora e visual multicanal de Luís Gomes da Costa, coordenador da Binaural/Nodar, que partiu de um trabalho de campo multidisciplinar.

\footnotetext{
${ }^{10}$ Escoitar: Escoitar é um coletivo que tem como premissas a investigação sobre a identidade sonora da Galícia e de refletir o entorno e as relações que estabelecem entre si quatro conceitos básicos: som, identidade, memória e lugar.

${ }^{11}$ Binaural Nodar: A Binaural Nodar é uma associação cultural sem fins lucrativos fundada em 2004 com o intuito de promover a exploração e a pesquisa nos domínios da arte sonora experimental, com especial ênfase na transversalidade de mídia e linguagens e na articulação entre a produção artística e o contexto envolvente.

${ }^{12}$ Luis Costa: Luís Gomes da Costa (1968). Presidente da Binaural - Associação Cultural de Nodar (São Pedro do Sul, Portugal). Curador, programador, organizador e documentarista sonoro e vídeo. Em 2006 decide voltar ao território das suas raízes, as montanhas dos maciços da Gralheira, Arada e Montemuro, para desenvolver projetos de documentação, reflexão e expressão contemporâneas, cruzando vivências cotidianas, criação artística e pesquisa territorial. Coordenador do Nodar Rural Art Lab, um espaço de pesquisa artística multimídia na aldeia rural de Nodar, que já acolheu mais de uma centena de artistas e investigadores.
} 
Alguns coletivos da Península Ibérica vem demostrando grande interesse na elaboração de propostas de interface midiática e cultural preocupadas com a questão patrimonial, tanto material quanto imaterial e natural. Outra reunião de artistas que vem se debruçando sobre as cartografias sonoras, sobre as paisagens sonoras, também está em solo Espanhol. Escuta Atenta, ${ }^{13}$ dirigida pelo fonografista, artista e compositor Juanjo Palacios e o artista valenciano Edu Comelles, está voltada ao ato da escuta atenta do mundo, preocupados e tomados pelas surpresas que o sentido da audição pode mostrar e abrir na percepção humana do espaço. Estes artistas, nos últimos anos, vêm desenvolvendo vários trabalhos de produção, investigação e educação centrados na cultura aural e na exploração do espaço sonoro.

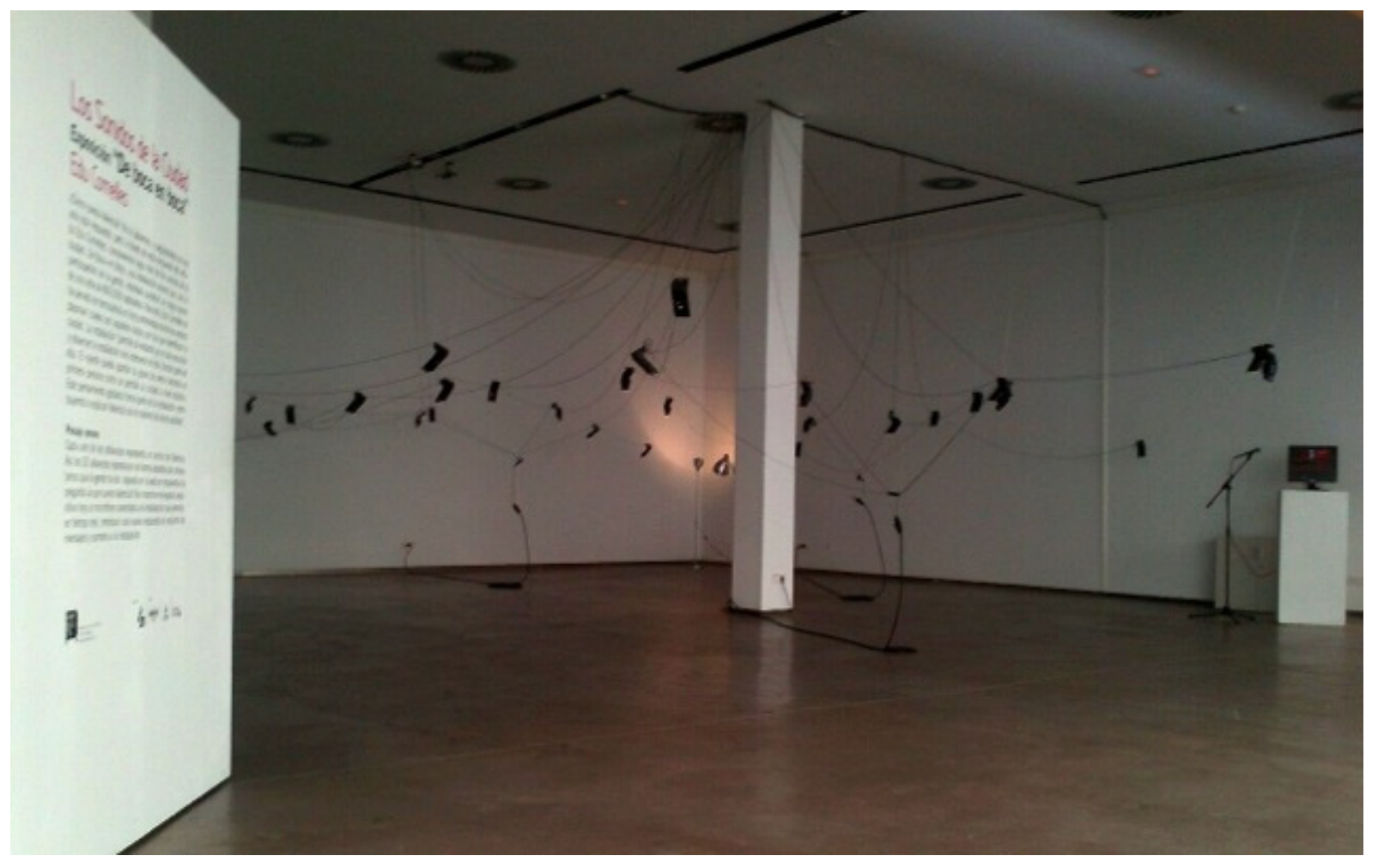

Figura 8 - 'De boca en boca': ¿A qué suena Valencia? Uma exposição de Edu Comelles. Sala de Exposiciones de Espai Rambleta (Valencia), 2015.

\footnotetext{
${ }^{13}$ Escuta Atenta: A Escucha Atenta (LEA) foi fundada em 2011 por Juanjo Palacios em formato de blog, com a idéia de servir de repositório de distintos projetos, documentos, recursos, etc, relacionados com a fonografia, as gravações de campo e a escuta ativa. Mais tarde se criou o LEA Cuestionario, onde pessoas que tem una relação ativa com o mundo da fonografía respondem a oito perguntas, compartilhando suas reflexões, experiências e ferramentas. Em 2012, em colaboração com Edu Comelles, nasce o LEA Ediciones, um catálogo de publicações online que pretende apresentar, em formato digital, trabalhos dentro do campo da fonografia e do paisagismo sonoro.
} 
Também em território espanhol localizamos os trabalhos desenvolvidos em Barcelona pelos artistas e escultores sonoros Josep Cerdá ${ }^{14}$ e Josep Manuel Berenguer ${ }^{15}$. Estes investigadores e artistas dirigem o Master em Arte Sonora ${ }^{16}$ na Universidad de Barcelona, oferecendo um programa interdisciplinar conjugado ao departamento de Arquitetura e Música desta Universidade. Em suas práticas pedagógicas são recorrentes as saídas a campo com alunos para ouvirem atentamente e registrarem os sons que habitam nos bairros de Barcelona. Esses sons registrados compõem um acervo sobre o patrimônio multicultural da cidade, assim como são utilizados em suas esculturas sonoras e criações fonográficas.

\section{CONSIDERAÇÕES FINAIS}

Alguns dos autores que aparecem aqui neste artigo e que também publicam nesta edição são atualmente parceiros de criações artísticas e intelectuais. É com grande alegria que compartilhamos suas ideias e propósitos. Numa sociedade onde impera-se o individualismo, objetivos como os de reunir e colaborar são já um bom começo para se seguir sonhando. Ao trazer para perto estes sujeitos pensadores promovemos a reunião, a comunhão e a partilha dos saberes produzidos. Ainda mais porque são saberes, intuições e pensamentos que apostam na esperança da construção de relações sociais mais humanas e respeitosas. Seguramente esta é a melhor colheita do labor de um pesquisador das áreas sociais e das artes pode alcançar: o perpetuar dos sonhos e da vontade se seguir criando e promovendo sonhos em outros sujeitos.

Este interesse em mapear, em cartografar lugares, sons, sentidos, sonhos, junta pesquisadores e artistas que vem demonstrando preocupações cada vez mais voltadas a propostas colaborativas. Nesta intersecção de interesses, os olhares acabam voltando-se para a qualidade de vida das pessoas, para a melhoria dos projetos urbanísticos, para a solução de problemas ambientais. Os olhares e preocupações dos artistas aproximam-se das leituras antropológicas e sociais, assim como de preocupações de alguns urbanistas e ecólogos. Todos

\footnotetext{
14 Ver artigo deste autor publicado nesta mesma edição: Observatorio de la transformación del sonido: La ciudad como texto, derivas, mapas y cartografia sonora.

${ }^{15}$ Ver entrevista oferecida por este autor especialmente para esta edição.

16 Master em Art Sonor: El Máster en Arte Sonoro de la UB, em colaboração com os Artistas Santa Mònica e Hangar se constitui no âmbito da criação para artistas sonoros emergentes. Dirigido a licenciados ou profissionais da música, da rádio, da tecnologia do som, das artes plásticas, a vídeo arte, a dança, o teatro ou a arquitetura interessados nas diversas modalidades de trabalho artístico com o som, tais como a arte sonora, a música experimental, a música acusmática, a poesia sonora, a performance, a paisagem sonora, a instalação ou os sistemas multimídia reativos e ou interativos, entre outros.
} 
com objetivos de elaborar propostas sensibilizantes para o público que acede acesse as pesquisas e criações.

Nossa itinerância por distintos departamentos acadêmicos e coletivos de artistas nos permite acessar às ideias expoentes de pensadores e criadores contemporâneos. Consequentemente auxilia-nos a elaborar nossos projetos e propostas de instalação interativa. As pesquisas realizadas pela antropóloga Cornélia Eckert, da Universidade Federal do Rio Grande do Sul, no Friedrichshain-Kreuzberg Museum ${ }^{17}$ em Berlin na Alemanha nos ilustra bem como uma pesquisa etnológica pode dialogar bem com as tecnologias desenvolvidas para a composição de cartografias interativas. Ekcert e Carvalho realizam suas pesquisas etnológicas citadinas se apropriando do modo de apreensão devaneante situacionistas, apoiando-se nas teorizações de Ricouer sobre identidade narrativa e utilizando dos recursos audiovisuais para registar e difundir seus resultados.

De similar modo, mas partindo de outro ponto de partida, encontramos as propostas cartográficas colaborativas que os artistas Josep Cerdá e a artista e curadora Lilian Amaral vem realizando em suas pesquisas e criações desde a perspectiva artística, e que podemos ver nas intervenções e pesquisas urbanas desenvolvidas por estes artistas individualmente e conjuntamente pelo projeto R.U.A. ${ }^{18}$ Estes dois artistas vem criando laços e convênios entre suas Universidades, e mesmo estando inseridos em departamentos de arte ambos demonstram interesses e preocupações voltados a questões sociais, urbanísticas, ambientais e patrimoniais.
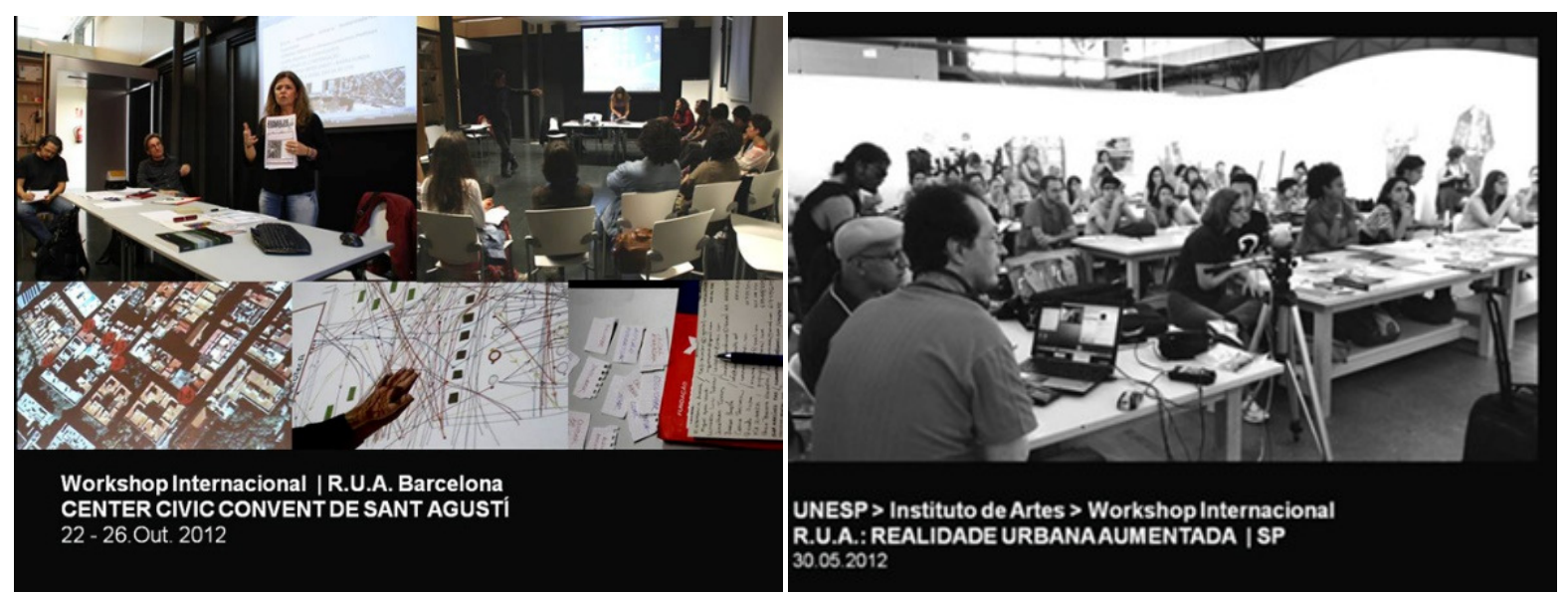

Figuras 9 e 10 - Workshop Internacional

\footnotetext{
${ }^{17}$ Ver artigo “A Poiésis De Um Museu De Bairro" de Ana Luiza Carvalho da Rocha e de Cornelia Eckert que compõem também essa edição.

${ }^{18}$ R.U.A: Realidade Urb Cartografias Inventadas, um projeto de Extensão Zonas de Compensação, organizado pelo GIIP - Grupo Internacional e Interinstitucional de Pesquisa em Convergência entre Arte, Ciência e Tecnologia do IA/UNESP e BR :: AC, Barcelona, Recerca, Art i Creació, Universidade de Barcelona.
} 
A rede vai tecendo encontros entre teóricos, pesquisadores e criadores, que investem seus dias e vidas, em propósitos colaborativos. E ela se enlarguece na medida da entrega e da confiança de que em outros rincões do mundo também outros pesquiadores também sigam realizando pesquisas semelhantes. É isso que ocorreu nesta trajetória empreendida nos últimos anos. Os fios tecidos reunidos aqui montam uma malha que trazem as cores, as formas, os sons das pesquisas feitas em Barcelona por Josep Cerdá e Josep Berenguer. Estas cores vem sendo misturadas com as impressões e caminhos empreendidos por Lilian Amaral em São Paulo e em Goias. Que consequentemente vem intercambiando com as inquietações e criações midiáticas realizadas Suzete Venturelli no Instituto das Artes e Miguel Gally do Departamento de Arquitetura e Urbanismo da Universidade de Brasília. E consequentemente por estes novos intercambios tecidos por nós neste artigo e nesta revista as antropologas Ekcert e Carvalho poderão acessar as elaborações que estes profissionais vem realizando desde suas áreas focais.

Concluindo, nossas pesquisas sobre autores, criadores, pesquisadores e teóricos que perpassam por metodologias e estudos cartográficos vão demonstrando deste modo uma perspectiva de abordagem transdiscipliar, colaborativa e com interesses similares em sus fundamentações que favoreçem o reconhecimento das subjetividades e de uma interação humana com o meio e com a diversidade cultural e social mais ética e poética. Reuní-los é retroalimentar nossos anseios, sonhos e esperanças, é propocionar mais diálogos, mais inquietações e mais intercâmbios.

\section{REFERÊNCIAS BIBLIOGRÁFICAS}

BACHELARD, G. A poética do espaço. São Paulo, Martins Fontes, 1993.

BOURRIAUD, N. A Estética Relacional. $1^{\mathrm{a}}$ ed. $1^{\mathrm{a}}$ reimp. Buenos Aires. Adriana Hidalgo Editora, 2008

. Radicante. $1^{\text {a }}$ Ed. Buenos Aires. Adriana Hidaldo Editora, 2009.

CERDÀ, J. Observatorio de la transformación urbana del sonido. La ciudad como texto, derivas, mapas y cartografía sonora. Revista Digital Arte e políticas de identidade. Universidad de Murcia. 2012 
DEBORD, Guy. Internacional Situacionista. vol. I: La realización del arte . Madrid: Literatura Gris, 1958.

DELEUZE, G. GUATTARI, F. Mil platôs (volume I). São Paulo: editora 34, 2000. Mil platôs (volume III). São Paulo: editora 34, 2000.

GUATTARI, F. ROLNIK, S. Cartografias do desejo. Petrópolis: Editora Vozes, 2000.

POL, E. La apropiación del espacio. En L. Íñiguez y E. Pol (Eds.), Cognición, epresentación y apropiación del espacio. Collecció Monografies Psico-Socio-Ambientals, Barcelona:Publicacions de la Universitat de Barcelona. 1996.

POL, E. El modelo dual de la apropiación del espacio. Psicología y Medio Ambiente. Aspectos psicosociales, educativos y metodológicos A Coruña: Asociación galega de estudios e investigación psicosocial, 2002.

RICOEUR, P. O si-mesmo como um outro. Tradução de Lucy Moreira Cesar. Campinas: Papirus, 1991.

\section{Catálogo Consultado}

Pedagogia no campo expandido / Organização: Pablo Helguera e Pablo Helguera, Mônica Hoff; tradução de Camila Pasquetti, Camila Schenkel, Carina, Alvarez, Gabriela Petit, Francesco Settineri, Martin Heuser e Nick Rands. Porto Alegre: Fundação Bienal de Artes Visuais do Mercosul, 2011.

Dossier Walkshop - Aqueduto das Águas Livres- Um percurso através das realidades materiais e imateriais da metrópole contemporânea Lisboa. Um projeto Stalker/OsservatorioNomade. Janeiro|Fevereiro 2010 arqa.

\section{Sites consultados}

http://www.sonoscop.net/sonoscop/sonidosencausa/index.html

http://mapof.tumblr.com

http://transductores.net

www.osservatorionomade.net/lisboa

http://mapasonoru.com/mapa.php

http://laescuchaatenta.com

https://corpocidade4.wordpress.com/apresentacao 